\title{
ANALISIS KOMPETENSI MAHASISWA PROGRAM STUDI PERHOTELAN
}

\author{
Kanah $^{1)}$, Ida Ayu Ketut Sumawidari') dan I Made Darma Oka ${ }^{3)}$ \\ 1), 2), 3)Program Studi Perhotelan, Politeknik Negeri Bali, Kampus Bukit Jimbaran, Badung \\ E-mail: ${ }^{1)}$ kanah@pnb.ac.id, ${ }^{3)}$ madedarmaoka@pnb.ac.id
}

\begin{abstract}
Hospitality Study Program of Bali State Polytechnic as vocational education institution always strives for the quality to fulfill the desired competence of the user (tourism industry). This study aims to analyze the student's competence of Hospitality Studies Program in the user. Through this analysis it is expected the management able to take the solution in order to improve the competence of the graduates. The study was conducted on student's semester VI who have been training in tourism industry. The sample was determined 107 people, using confirmatory factor analysis. The results showed that the three factors are attitude, knowledge, and skill had a significant influence to the achievement of the students' competency. The most dominant factor determining student competence is skill factor, followed by knowledge factor, and then an attitude factor. Thus, it is suggested to the management to emphasize the attitude factor in providing education and training at the campus in order to win an increasingly competitive competition. To the lecturers, especially the lecturers of professional ethics subjects, it is expected to further improve the discipline and attitude of the students so that they can fulfill the competence according to the expectations of the user.
\end{abstract}

Keywords: Analysis, competence, student, user

\begin{abstract}
Abstrak
Program Studi Perhotelan Politeknik Negeri Bali sebagai lembaga pendidikan vokasi selalu berusaha agar mutu lulusannya mampu memenuhi kompetensi yang diinginkan pihak pengguna (industri pariwisata). Penelitian ini bertujuan untuk menganalisis kompetensi mahasiswa Program Studi Perhotelan di industri pariwisata. Melalui analisis ini diharapkan pihak manajemen Program Studi Perhotelan mampu mengambil solusi guna dapat meningkatkan kompetensi lulusan. Penelitian dilakukan terhadap mahasiswa semester VI Program Studi Perhotelan yang telah dan sedang melaksanakan on the job training di industri pariwisata. Sampel penelitian ditetapkan sebanyak 107 orang, dengan menggunakan confirmatory factor analysis. Hasil penelitian menunjukkan bahwa ketiga faktor baik faktor attitude, knowledge, maupun skill memberikan pengaruh signifikan terhadap pencapaian kompetensi mahasiswa Program Studi Perhotelan. Faktor yang paling dominan menentukan kompetensi mahasiswa adalah faktor skill, disusul faktor knowledge, dan selanjutnya adalah faktor attitude. Dengan demikian disarankan kepada manajemen Program Studi Perhotelan Politeknik Negeri Bali untuk lebih menekankan pada faktor attitude dalam memberikan pendidikan dan pelatihan di kampus Politeknik Negeri Bali guna mampu memenangi persaingan yang semakin kompetitif. Kepada para dosen Program Studi Perhotelan terutama dosen pengampu mata kuliah etika profesi, diharapkan lebih meningkatkan disiplin serta
\end{abstract}


sikap/attitude mahasiswa sehingga mampu memenuhi kompetensi sesuai harapan dari pihak pengguna (industri pariwisata)..

Kata kunci: Analisis, kompetensi, mahasiswa, industri pariwisata

\section{PENDAHULUAN}

\section{Program Studi Perhotelan Politeknik} Negeri Bali sebagai lembaga penyelenggara pendidikan tinggi bidang vokasi selalu berusaha untuk meningkatkan mutu lulusannya. Dalam peningkatan mutu lulusan tersebut ada tiga hal yang perlu diperhatikan yaitu: input, proses, dan output. Penilaian kualitas lulusan tidak hanya dilihat dari faktor internal namun juga yang tidak kalah penting adalah penilaian dari pihak eksternal yang berperasn sebagai user lulusan. Oleh karena itu untuk dapat meningkatkan mutu lulusan (output) Program Studi Perhotelan, perlu meminta masukan dan saran dari pihak eksternal (user) dalam hal ini adalah pihak industri pariwisata sehingga hasilnya lebih objektif. Peran pihak user sangat penting dalam memberi masukan untuk membentuk mutu lulusan berkualitas sesuai tuntutan kebutuhan industri yang selalu berkembang.

Dalam menilai kualitas lulusan suatu lembaga pendidikan dapat dilihat dari sejauhmana lulusan yang dihasilkan diserap oleh pihak user, karena pihak user-lah yang menilai kelayakan kerja yang dibutuhkan dalam industri pariwisata. Kerangka konsep berpikir yang sering digunakan oleh pihak user adalah Taxonomy Bloom. Taxonomy Bloom adalah stuktur hierarki yang mengidentifikasi skill mulai dari tingkat yang paling rendah hingga yang tinggi (http//:en.wikipedia.org/wiki/Bloom).

Bloom membagi kerangka konsep ini menjadi tiga domain yaitu kemampuan kognitif (knowledge), afektif (attitude), dan psikomotorik (skill). Ketiga domain tersebut saling komplementer dalam menentukan tingkat profesionalisme dari seseorang tenaga kerja. Untuk dapat mengisi peluang kerja di industri pariwisata, lulusan Program Studi Perhotelan diwajibkan memiliki kualifikasi kompetensi kerja seperti hard skill dan soft skill. Dalam pembelajaran Oka dan Winia (2013); Oka, dkk. (2017) menyebutkan bahwa pencapaian kompetensi kerja akan lebih efektif dan efisien dengan menerapkan pembelajaran berbasis multimedia melalui aplikasi model pembelajaran terpadu (integrated learning) dengan melibatkan beberapa dosen terkait.

Guna mencapai kompetensi yang diharapkan sesuai dengan capaian pembelajaran yang telah ditetapkan maka terdapat beberapa faktor yang perlu diperhatikan dalam pembelajaran. Beberapa faktor yang menyebabkan proses belajar mengajar dapat berjalan sebagaimana yang diharapkan, yaitu faktor guru/dosen, faktor siswa, faktor sarana-prasarana yang tersedia serta faktor lingkungan yang kurang mendukung. Keempat faktor tersebut saling mendukung dan saling melengkapi guna mampu meningkatkan mutu lulusan sesuai dengan target yang ditetapkan.Guru/dosen adalah komponen yang sangat penting dalam proses belajar mengajar (PBM). Keberhasilan dalam proses belajar mengajar di sekolah/kampus sangat tergantung pada kepiawaian guru dalam menggunakan metode, teknik dan strategi pembelajaran yang tepat sesuai dengan karakter para pebelajar. Guru dalam proses pembelajaran memegang peran yang strategis, selain sebagai row model atau teladan bagi siswanya juga sebagai pengelola dari pembelajaran sehingga proses pembelajaran menjadi efektif dan 
efisien. Keberhasilan suatu proses pembelajaran sangat ditentukan oleh kualitas dan kemampuan yang dimiliki oleh guru. Hal ini sesuai dengan yang pernyataan Kirby (Wina, 2006: 50) yang menyebutkan bahwa: "one underlying emphasis should be noticeable: that the quality of the teacher is the essential, constant feature in the success of any educational system."

Berdasarkan paparan di atas, salah satu alternatif untuk meningkatkan kualitas lulusan mahasiswa Pogram Studi Perhotelan agar mampu bersaing secara kompetitif di dunia industri adalah dengan cara menemukenali eksistensi mahasiswa saat melakukan on the job training yaitu menganalisis tentang faktor-faktor yang menjadi penilaian pihak user terhadap kompetensi mahasiswa Program Studi Perhotelan di industri pariwisata. Kompetensi mahasiswa tersebut ditinjau dari aspek attitude, knowledge, dan skill yang dimiliki dari penilaian pihak user selaku pengguna yang mensupervisi langsung kegiatan mahasiswa pada saat on the job training.

\section{METODE PENELITIAN}

Seluruh populasi mahasiswa Program Studi Perhotelan Politeknik Negeri Bali semester VI tahun akademik 2017/2018 yaitu sebanyak 108 orang (PS. Perhotelan, 2018). Dari 108 orang populasi tersebut satu orang training di Thailand sehingga yang dijadikan sampel dalam penelitian ini sebanyak 107 orang. Solimun (2002) yang mengungkapkan bahwa sampel yang layak untuk diteliti melalui analisis faktor adalah minimal sebanyak 5 kali jumlah variabel. Penelitian ini menggunakan 24 variabel, tetapi karena jumlah populasi yang terbatas maka pengambilan sampel menggunakan metode sensus. Dalam menganalisis kompetensi mahasiswa dipergunakan Confirmatory Factor Analysis (CFA) dengan program SPPS. Analisis kompetensi mahasiswa, dibuat dalam variabel X1 s/d X24. Dengan telah ditetapkannya tiga common faktor yaitu faktor attitude (F1), knowledge (F2), serta faktor skill (F3) menghasilkan beberapa hasil uji konfirmasi. Melalui analisis faktor dapat diketahui faktor-faktor dan variabel yang memengaruhi pencapaian kompetensi mahasiswa Program Studi Perhotelan Politeknik Negeri Bali.

\section{HASIL DAN PEMBAHASAN}

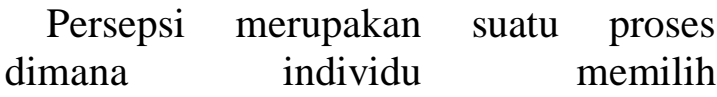
mengorganisasikan, serta mengartikan stimulus yang diterima melalui alat inderanya menjadi suatu makna (Rangkuti, 2003). Meskipun demikian makna dari proses persepsi tersebut juga dipengaruhi oleh pengalaman masa lalu dari individu yang bersangkutan terhadap aktivitas yang diamati. Persepsi merupakan daya tanggap atau penilaian dari pihak user terhadap kompetensi mahasiswa Program Studi Perhotelan Politeknik Negeri Bali saat melaksanakan on the job training di industri pariwisata setelah melalui proses pengkajian yang tajam terhadap objek yang diamati. Objek yang dimaksud adalah kemampuan mahasiswa Program Studi Perhotelan dalam melakukan pekerjaan selama on the job training di industri baik dari domain attitude, knowledge, and skill.

Pihak pengguna (user) yang dimaksud adalah pihak industri pariwisata tempat mahasiswa Program Studi Perhotelan melakukan on the job training. Industri pariwisata adalah sistem dari berbagai elemen yang tersusun seperti sarang labalaba: "like a spider's web-touch one part of it and reverberations will be felt throughout the system" (Mill \& Morrison, 2012: 3). Oleh karena itu setiap tenaga kerja yang bekerja di industri pariwisata harus memiliki kompetensi sesuai dengan bidang pekerjaannya.

Standar kompetensi diartikan sebagai suatu ukuran atau patokan tentang pengetahuan, keterampilan, dan sikap kerja yang harus dimiliki untuk 
mengerjakan suatu pekerjaan di tempat kerja yang akan dipelajari dalam pelatihan (BKSP, 2011). Standar kompetensi tidak berarti hanya kemampuan menyelesaikan suatu tugas, tetapi dilandasi pula bagaimana serta mengapa tugas itu dikerjakan. Dengan kata lain, standar kompetensi meliputi faktor-faktor yang mendukung seperti pengetahuan dan kemampuan untuk mengerjakan suatu tugas dalam kondisi normal di tempat kerja serta kemampuan mentransfer dan menerapkan kemampuan dan pengetahuan pada situasi dan lingkungan yang berbeda. Standar kompetensi merupakan rumusan tentang kemampuan yang harus dimiliki seseorang untuk melakukan suatu tugas/pekerjaan yang dilandasi oleh ilmu pengetahuan, keterampilan, dan sikap kerja, sesuai dengan kriteria unjuk kerja yang dipersyaratkan.

Sidharta dan Lusyana (2014) menyebutkan bahwa kompetensi merupakan salah satu faktor penentu dalam keberhasilan usaha khususnya UMKM. Dengan memiliki kompetensi yang memadai akan menghasilkan kinerja yang optimal bagi usaha. Dalam penelitiannya disebutkan besarnya pengaruh faktor yang mempengaruhi kompetensi berdasarkan pada konsep pengetahuan (knowledge), keterampilan (skill), dan kemampuan (ability) di Sentra Kaos Suci Bandung. Hasil penelitiannya menunjukkan bahwa faktor yang baling besar pengaruhnya adalah kemampuan (ability), sedangkan faktor yang memiliki pengaruh paling kecil adalah faktor pengetahuan (knowledge) atas kompetensi pelaku UMKM di Sentra Kaos Suci Bandung. Sedangkan Muluk, dkk. (2016) menyebutkan bahwa masih terdapat kesenjangan antara kompetensi yang dimiliki oleh lulusan dengan kebutuhan yang sebenarnya dari dunia kerja bagi lulusan Prodi Administrasi Publik Universitas Brawijaya Malang. Lebih lanjut disebutkan bahwa untuk mengantisipasi sekaligus mengatasinya perlu dilakukan suatu kajian yang komprehensif yang melibatkan tiga unsur, yakni learning outcome (LO) program studi, kompetensi yang diinginkan oleh dunia kerja, dan kondisi nyata lulusan saat ini.

Sebelum dibahas secara mendetail tentang analisis kompetensi mahasiswa Program Studi Perhotelan Jurusan Pariwisata Politeknik Negeri Bali oleh pihak pengguna (user), terlebih dahulu diuraikan kemampuan dari instrumen (kuesioner) yang dipergunakan. Kegiatan ini diawali dengan melakukan uji validitas dan uji realibilitas. Hasil pengujian menunjukkan bahwa pada faktor attitude yang terdiri dari 8 variabel atau indikator ternyata memiliki tingkat signifikan berupa nilai apha sebesar 0,887. Pada faktor knowledge dengan jumlah variabel sebanyak 8 variabel memiliki nilai apha cronbach sebesar 0,869. Faktor keterampilan (skill) terdiri atas 8 variabel menunjukkan bahwa faktor ini menghasilkan tingkat signifikansi sebesar 0,824 . Berdasarkan hasil uji validitas dan reliabilitas maka dapat disimpulkan bahwa instrumen penelitian memiliki kepatutan (valid) karena mampu menghasilkan produk momen yang baik dan memiliki kelayakan (reliabel) karena nilainya relatif konsisten yaitu berada di atas 0,600. Dengan terpenuhinya hasil validitas dan reliabilitas maka penelitian ini tetap menggunakan instrumen berupa kuesioner.

Dari masing-masing faktor juga ditunjukkan pengaruh variabel yang memberi kontribusi terhadap faktor-faktor yang memengaruhi kompetensi mahasiswa Program Studi Perhotelan yang diujikan dalam penelitian. Uji KMO yang dilakukan terhadap masing-masing variabel mendapatkan hasil uji dimana variabel-variabel pembentuk faktor attitude memperoleh hasil sebesar 0,699. Uji Bartlett menghasilkan nilai signifikansi sebesar 0,000. Pada variabelvariabel pembentuk faktor knowledge menghasilkan uji KMO sebesar 0,749 dan 
pada uji Bartlett memperoleh nilai signifikansi sebesar 0,000. Demikian juga pada faktor skill, hasil yang diperoleh adalah dari uji KMO adalah sebesar 0,771 dan dengan nilai signifikansi sebesar 0,000. Nilai yang dihasilkan dari uji KMO pada masing-masing faktor tersebut menggambarkan bahwa hasilnya di atas 0,05 . Nilai ini menggambarkan bahwa ketiga faktor (attitude, knowledge, and skill) dalam penelitian ini memiliki ketepatan model terhadap analisis yang digunakan, artinya bahwa masing-masing faktor memberi pengaruh nyata terhadap kompetensi mahasiswa Program Studi Perhotelan.

Dari sejumlah pertanyaan yang disampaikan melalui kuesioner atau daftar pertanyaan, pihak pengguna memberikan jawaban tentang faktor-faktor yang berpengaruh kompetensi mahasiswa Program Studi Perhotelan. Tingkat pendapat pihak pengguna yang dirasakan secara kualitatif diklasifikasikan ke dalam lima tingkat mulai dari sangat setuju, setuju, ragu-ragu, kurang setuju, dan tidak setuju. Hasil seluruh analisis statistik dan data frekwensi dari seluruh variabel tersebut lebih jelas diuraikan secara naratif verbal dalam interpretasi masingmasing faktor, yaitu:.

\section{Faktor Attitude}

Hasil analisis terhadap masing-masing variabel yang ditunjukkan pada $\mathrm{X} 1, \ldots \mathrm{X} 8$ didapatkan satu komponen faktor yang menentukan pada faktor attitude, dengan nilai akar ciri (eigen value) yang dapat menerangkan keragaman yaitu sebesar 46,591\%. Dari hasil olah data terhadap kedelapan (8) variabel yang ditentukan dalam faktor attitude dapat dilihat bahwa masing-masing variabel pada faktor attitude memberi pengaruh signifikan terhadap kompetensi mahasiswa Program Studi Perhotelan Politeknik Negeri Bali kecuali variabel X1 dan X4. Kontribusi atau sumbangan nilai secara kumulatif dari seluruh variabel pada faktor attitude adalah sebesar 46,591. Hal ini menunjukkan bahwa nilai ciri (eigen value) dari masing-masing variabel yang ditunjukkan melalui kontribusi nilai masing-masing komponen secara kumulatif faktor attitude memberi nilai pengaruh signifikan terhadap kompetensi mahasiswa Program Studi Perhotelan Politeknik Negeri Bali.

Untuk melihat besarnya pengaruh dari masing-masing variabel pada faktor attitude terhadap kompetensi mahasiswa Program Studi Perhotelan Politeknik Negeri Bali, maka dapat dilihat pada Tabel 1.

Tabel 1. Koefisien Korelasi (Komponen Matriks) Faktor Sikap

\begin{tabular}{lccc}
\hline \multicolumn{1}{c}{ Indikator Variabel Faktor Sikap } & $\begin{array}{c}\text { Koefisien } \\
\text { korelasi }\end{array}$ & Ditetapkan & Keterangan \\
\hline Memiliki penampilan rapi dan menarik (X1) & 0,196 & $>0,600$ & Tidak Signifikan \\
Memiliki etika, sopan santun, dan murah senyum (X2) & 0,820 & $>0,600$ & Signifikan \\
Mampu bekerjasama sesama kolega/staf (X3) & 0,749 & $>0,600$ & Signifikan \\
Memiliki integritas dan disiplin tinggi (X4) & 0,484 & $>0,600$ & Tidak Signifikan \\
$\begin{array}{l}\text { Memiliki tanggung jawab tinggi terhadap pekerjaan (X5) } \\
\text { Memiliki etos kerja yang baik (X6) }\end{array}$ & 0,831 & $>0,600$ & Signifikan \\
$\begin{array}{l}\text { Memiliki rasa percaya diri yang tinggi (X7) } \\
\begin{array}{l}\text { Memiliki attitude yang lebih baik dibandingkan dengan } \\
\text { mahasiswa dari perguruan tinggi sejenis (X8) }\end{array}\end{array}$ & 0,809 & $>0,600$ & Signifikan \\
\hline
\end{tabular}
Sumber: Data análisis faktor 
Selanjutnya dijelaskan secara rinci pengaruh dari masing-masing variabel dalam penelitian untuk masing-masing faktor yang dianalisis. Untuk faktor attitude, dari kedelapan variabel yang ditetapkan dalam penelitian terdapat 6 variabel yang berpengaruh signifikan terhadap kompetensi mahasiswa, yaitu: mehasiswa memiliki etika, sopan santun dan murah senyum (X2), mampu bekerjasama sesama kolega/staf (X3), memiliki tanggungjawab tinggi terhadap pekerjaan (X5), memiliki etos kerja yang baik (X6), memiliki rasa percaya diri yang tinggi (X7), dan memiliki attitude yang lebih baik dibandingkan dengan mahasiswa dari perguruan tinggi lain (X8). Selanjutnya jika dirangking dari ke8 variabel yang diuji (X1...X8) dalam faktor attitude, ternyata variabel memiliki tanggungjawab tinggi terhadap pekerjaan (X5) memiliki pengaruh yang paling tinggi $(0,831)$ terhadap kompetensi mahasiswa Program Studi Perhotelan.

\section{Faktor Pengetahuan (Knowledge)}

Hasil uji yang dilakukan terhadap faktor knowledge berada di atas nilai yang ditetapkan oleh model analisis yang digunakan yaitu sebesar 0,05. Nilai ini memberi arti bahwa faktor knowledge secara statistik memiliki ketepatan model dengan tingkat signifikansi sebesar 0,000. Selanjutnya hasil analisis faktor terhadap indikator variabel X9, X10, X10, X11, X12, X13, X14, X15 dan X16 didapatkan satu komponen faktor yang menentukan faktor knowledge (F2), dengan nilai akar ciri (eigen value) yang dapat menerangkan keragaman total sebesar 44,639\%. Total variance dari faktor sarana dan prasarana adalah $44,639 \%$ dan nilai komulatif eigen value yang dihasilkan sebesar 44,639. Ini berarti bahwa nilai ciri dari faktor knowledge memberi pengaruh signifikan terhadap kompetensi mahasiswa. Faktor knowledge yang terdiri dari 8 variabel $(\mathrm{X} 9, . . \mathrm{X} 16)$ dimaknai dengan komponen matriks (koefisien korelasi) yang lebih besar dari yang ditetapkan $(0,600)$, kecuali X16. Kontribusi masing-masing variabel pada faktor F2, yaitu:

Tabel 2. Koefisien Korelasi (Komponen Matriks) Faktor Pengetahuan

\begin{tabular}{|c|c|c|c|}
\hline Indikator Variabel Faktor Pengetahuan & $\begin{array}{l}\text { Koefisien } \\
\text { korelasi }\end{array}$ & Ditetapkan & Keterangan \\
\hline Memiliki pengetahuan luas tentang perhotelan (X9) & 0,714 & $>0,600$ & Signifikan \\
\hline $\begin{array}{l}\text { Memiliki pengetahuan tentang operasional front office } \\
\text { (X10) }\end{array}$ & 0,715 & $>0,600$ & Signifikan \\
\hline Memiliki pengetahuan operasional housekeeping (X11) & 0,549 & $>0,600$ & $\begin{array}{l}\text { Tidak } \\
\text { Signifikan }\end{array}$ \\
\hline Memiliki pengetahuan operasional food \& beverage (X12) & 0,673 & $>0,600$ & Signifikan \\
\hline Memiliki pengetahuan teknologi informasi (X13) & 0,622 & $>0,600$ & Signifikan \\
\hline Memiliki pengetahuan manajemen perhotelan (X14) & 0,728 & $>0,600$ & Signifikan \\
\hline $\begin{array}{l}\text { Memiliki pengetahuan bahasa Inggris sesuai bidang kerja } \\
\text { (X15) }\end{array}$ & 0,628 & $>0,600$ & Signifikan \\
\hline $\begin{array}{l}\text { Memiliki pengetahuan yang lebih baik dibandingkan } \\
\text { dengan mahasiswa dari perguruan tinggi sejenis (X16) }\end{array}$ & 0,697 & $>0,600$ & Signifikan \\
\hline
\end{tabular}

Sumber: Diolah dari hasil analisis faktor

Dengan nilai komponen matriks yang berada di atas yang ditetapkan, berarti bahwa variabel X9, X10, X12, X13, X14, $\mathrm{X} 15$, dan X16 berpengaruh nyata terhadap kompetensi mahasiswa Program Studi Perhotelan Politeknik Negeri Bali, sedangkan variabel X11 berpengaruh tidak nyata. Selanjutnya jika dirangking 
dari ke-8 variabel yang diuji (X9...X16) dalam faktor knowledge, ternyata variabel mahasiswa memiliki pengetahuan manajemen perhotelan (X9) memiliki pengaruh yang paling tinggi terhadap pencapaian kompetensi mahasiswa Perhotelan Politeknik Negeri Bali.

\section{Faktor Keterampilan (Skill)}

Pengujian secara parsial tentang ketepatan model yang digunakan dari faktor skill, diperoleh hasil uji ketepatan yaitu uji KMO adalah sebesar 0,771 dan dengan nilai signifikansi sebesar 0,000 .
Hasil analisis faktor terhadap delapan variabel yang diamati (X17 sampai X24) didapatkan satu komponen faktor yang menentukan variabel yang tercakup dalam faktor skill dengan nilai akar ciri yang dapat menerangkan keragaman total sebesar 45,872\%. Pengaruh dari masingmasing variabel (X17,...X24) terhadap kompetensi mahasiswa yang terkait dengan faktor skill ditunjukkan dengan nilai koefisien korelasi atau komponen matriks (Tabel 3).

Tabel 3. Komponen Matriks (Koefisien Korelasi) Faktor Skill

\begin{tabular}{|c|c|c|c|}
\hline Indikator Variabel Faktor Keterampilan & $\begin{array}{c}\text { Koefisien } \\
\text { korelasi }\end{array}$ & Ditetapkan & Keterangan \\
\hline Mampu menerapkan skill bidang perhotelan dengan baik (X17) & 0,757 & $>0,600$ & Signifikan \\
\hline Mampu melakukan pekerjaan bidang front office (X18) & 0,726 & $>0,600$ & Signifikan \\
\hline Mampu melakukan pekerjaan bidang housekeeping (X19) & 0,698 & $>0,600$ & Signifikan \\
\hline Mampu melakukan pekerjaan bidang food production (X20) & 0,563 & $>0,600$ & $\begin{array}{l}\text { Tidak } \\
\text { Signifikan }\end{array}$ \\
\hline Mampu beradaptasi dengan teknologi informasi di hotel (X21) & 0,619 & $>0,600$ & Signifikan \\
\hline Mampu me-manage staf/pekerjaan di hotel dengan baik (X22) & 0,637 & $>0,600$ & Signifikan \\
\hline $\begin{array}{l}\text { Mampu berkomunikasi bahasa Inggris sesuai bidang kerja } \\
\text { (X23) }\end{array}$ & 0,768 & $>0,600$ & Signifikan \\
\hline $\begin{array}{l}\text { Memiliki skill yang lebih tinggi dibandingkan dengan } \\
\text { mahasiswa dari perguruan tinggi sejenis (X24) }\end{array}$ & 0,622 & $>0,600$ & Signifikan \\
\hline
\end{tabular}

Sumber: Data hasil analisis faktor

Untuk faktor skill, dari kedelapan variabel yang ditetapkan dalam penelitian (X17...X24) terdapat 7 variabel yang berpengaruh signifikan terhadap kompetensi mahasiswa, yaitu: mampu menerapkan skill bidang perhotelan dengan baik (X17), mampu melakukan pekerjaan bidang front office (X18), mampu melakukan pekerjaan bidang housekeeping (X19), mampu beradaptasi dengan teknologi dan informasi (X21), mampu me-manage staf/pekerjaan dengan baik (X22), mampu berkomunikasi bahasa Inggris sesuai bidang kerja (X23), dan memiliki skill yang lebih baik dibandingkan dengan mahasiswa dari perguruan tinggi lain (X24). Selanjutnya jika dirangking dari ke-8 variabel yang diuji dalam fakto skill, ternyata variabel mampu berkomunikasi dalam bahasa Inggris sesuai bidang kerja (X23) memiliki pengaruh yang paling tinggi $(0,768)$ terhadap kompetensi mahasiswa Program Studi Perhotelan.

\section{KESIMPULAN DAN SARAN}

Berdasarkan hasil analisis atau kajian di atas dengan mengacu kepada rumusan permasalahan, maka dapat diuraikan beberapa simpulan terkait dengan penelitian ini, yaitu:

a. Ketiga faktor yang diujikan dalam penelitian ini (faktor attitude, knowledge, and skill) memberi pengaruh signifikan terhadap 
kompetensi mahasiswa Program Studi Perhotelan Politeknik Negeri Bali. Dari ketiga faktor yang diujikan tersebut ternyata faktor skill yang paling dominan memberi pengaruh, terhadap kompetensi mahasiswa.

b. Untuk faktor attitude, dari ke-8 variabel yang ditetapkan, variabel yang memberi pengaruh paling dominan terhadap pencapaian kompetensi mahasiswa yaitu variabel mahasiswa memiliki tanggungjawab yang tinggi terhadap pekerjaan yang diberikan oleh atasan (X5), sedangkan variabel yang memberi pengaruh paling kecil adalah mahasiswa memiliki penampilan yang rapi dan menarik. Untuk faktor knowledge, dari ke-8 variabel yang ditetapkan, variabel yang berpengaruh paling dominan adalah vaiabel mahasiswa memiliki pengetahuan manajemen perhotelan (X14) dan variabel yang paling kecil pengaruhnya adalah mahasiswa memiliki pengetahuan housekeeping. Sedangkan untuk faktor skill, dari ke8 variabel yang diujikan, variabel yang memberi pengaruh paling dominan adalah mahasiswa mampu berkomunikasi dalam bahasa Inggris sesuai dengan bidang kerja (X23), dan yang berpengaruh paling rendah adalah mahasiswa mampu melakukan pekerjaan bidang food production (X20).

Disarankan kepada pihak manajemen Program Studi Perhotelan hendaknya lebih memperhatikan tentang keberadaan attitude mahasiswa ke depan, karena sikap mahasiwa merupakan faktor penting dalam menentukan pencapaian kompetensi mahasiswa untuk mengantisipasi persaingan yang semakin kompetitif. Para dosen terutama dosen pengampu mata kuliah etika profesi, diharapkan selalu meningkatkan disiplin agar attitude mahasiswa mampu memenuhi kompetensi sesuai harapan dari pihak industri pariwisata. Pihak lembaga harus memberikan dukungan dalam pengembangan sikap, pengetahuan, dan keterampilan mahasiswa untuk memenuhi tuntutan industri pariwisata yang selalu berkembang.

\section{UCAPAN TERIMAKASIH}

Terima kasih disampaikan kepada Direktorat Jenderal Riset Pengabdian Masyarakat Pendidikan Tinggi serta para responden yang telah membantu dalam memberikan informasi dan data yang diperlukan. Hal yang sama disampaikan kepada semua pihak lainnya yang telah mendukung dalam penulisan artikel ini.

\section{DAFTAR PUSTAKA}

BKSP (Badan Koordinasi Sertifikasi Profesi). 2011. Percepatan dan Pengembangan Kompetensi SDM Indonesia. Semarang: Kadin Jawa Tengah-DIHK Jerman

Bloom's Taxonomy-Wikipedia, the free encyclopedia from http://en.wikipedia.org/wiki/Bloom, diakses tanggal 22 Januari 2018

Mill, R. C. dan Morrison, A. M. 2012. The Tourism System. United States of America: Kendall Hunt Publising Company. Seventh edition.

Muluk, M.R.K., M.C. Ulum, dan N. Widodo. 2016. Graduate Employability pada Lulusan Program Studi Administrasi Publik Fakultas Ilmu Administrasi Universitas Brawijaya Tahun 2015. Jurnal Ilmiah Administrasi Publik.Vol. 2 (3), hal. 88-99.

Oka, I.M.D., Darma, I.N.W.I.M. and Oka, I., 2013. Pengembangan Modul Pembelajaran Tata Hidangan Berbasis Multimedia untuk Meningkatkan Kompetensi Mahasiswa Program Studi Perhotelan Politeknik Negeri Bali (Persepsi Mahasiswa Terhadap Modul Tata Hidangan). Jurnal Teknodik, pp.133-144. 
Oka, I.M.D., Sadia, I.K. and Pugra, I.W., 2017. Integrated Practice Learning Model to Improve Waiter/S'competency on Hospitality Study Program, Politeknik Negeri Bali. International Journal of Applied Sciences in Tourism and Events, 1(2), p.171.

Pitana, I G. dan Diarta, I K. S. 2009. Pengantar Ilmu Pariwisata. Yogyakarta: Andi.

Rangkuti, F., 2003, Measuring Customer Satisfaction: Gaining Customer Relationship Strategy, Jakarta: Gramedia Pustaka Utama

Sidharta, I. dan Lusyana, D. 2014. Analisis Penentu Faktor Kompetensi Berdasarkan Knowledge, Skill, dan Attitude (KSA) di Sentra Kaos Suci Bandung. Jurnal Compotech \& Bisnis, Vol. 8 (1), hal. 49-60.

Solimun. 2002. Multivariate Analisis, Structural Equation Modeling (SEM) Lisrel dan Amos. Malang: Brawijaya FMIPA

Wina, S. 2006. Strategi Pembelajaran Berorientasi Standar Proses Pendidikan. Jakarta: Kencana Prenada Media. 

Analisis Kompetensi Mahasiswa... 